\section{Matt black dental instruments}

International surgical instruments manufacturer ISFY has launched a stylish range of matt black finished instruments.

The finish is achieved by coating each instrument in matt black titanium, which also provides excellent corrosion resistance.

The company's entire collection of dental instruments is available in the new finish, including orthodontic, extraction, periodontal, restorative and hygiene instruments.

ISFY's universal dental syringe, which takes both $1.8 \mathrm{ml}$ and $2.2 \mathrm{ml}$ vials, has interchangeable threads and a removable handle insert to aid dentists with small hands, is also available in the matt black finish.

ISFY has built a reputation for manufacturing high performance, attractive yet cost effective products. Every item goes through a rigorous four-step quality control process, and each is offered with an industry leading warranty of between two and seven years.

Barry Oates, Commercial Director - Global Operations for ISFY International, hopes that the new black finish will be popular with dentists looking to set themselves apart from other practices.

To find a distributor in your area, visit www.isfy.co.uk.

\section{Mint and gum manufacturer focus on dental health}

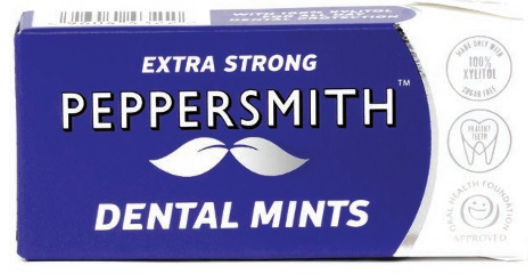

Peppersmith mints and gum has announced its new positioning to focus on dental health. The move comes alongside a packaging refresh, NPD and a new listing in the Waitrose dental category. Launching as part of a wider campaign to bring style and substance to people's dental routines, Peppersmith aims to inspire a healthy teeth revolution with its dental mints and gum.

Known for their naturally derived, sugar and aspartame free mints and gum, Peppersmith are looking to raise awareness of their products as part of our dental health routines, in addition to being a breath freshener. Accredited by the Oral Health Foundation, Peppersmith mints and gums are made with $100 \%$ xylitol. Xylitol is a natural alternative to sugar that is proven to actively reduce the risk of plaque and protect teeth from damage caused by eating and drinking.

Peppersmith's mission is to inspire a healthy teeth revolution by highlighting that brushing isn't enough to take care of our teeth. The whole range has been refreshed with new packaging and a new product: Strawberry Pastilles. A pastille with natural strawberry flavouring, it is the first fruit flavoured line extension from the mint and gum brand. Strawberry is currently available from peppersmith.co.uk and from health and wholefood retailers.

\section{For a super dry oral environment}

Drydent Sublingual is now available in the UK. Drydent Sublingual has gained acknowledgement all around Europe for its innovative and special features, and received an award at the Clinical Innovations Conference in London earlier this year. It is a unique product which collects and controls the saliva produced by the sublingual glands. It is placed under the tongue for the optimal collection of unwanted moisture under the sublingual area, providing a super dry oral environment during a variety of procedures.

Find Drydent at The Dental Directory. It comes in two different versions: Drydent Sublingual and Drydent Parotid. More information can be found at http://www. directadental.se/products/drydent.

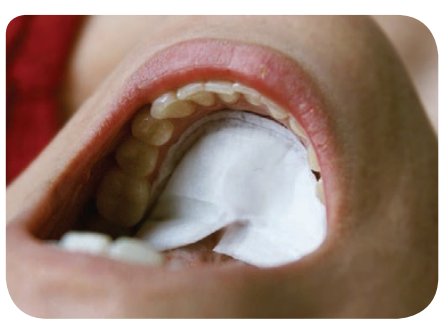

\section{An innovation in mouth cleansing}

The MC3 is an ergonomically designed Class 1 medical device for use in delivering safe mouth care. Unlike brushes, it cleans the tissues and collects debris simultaneously and unlike sponge swabs, the cleaning head of the MC3 will not detach and form a safety hazard.

The MC3 was developed following a medical safety alert from the Medicines and Healthcare Products Regulatory Agency involving the use of foam mouth swabs. A foam head had detached from the stick of an oral swab while a carer was providing mouth care to an elderly patient. The foam head could not be retrieved and the patient subsequently died. Over 800 patient safety incidents have been reported by The National Patient Safety Agency where the foam head had either become detached or pieces of the foam head were torn off and retained or lodged in the mouth. Foam mouth swabs have now been banned across Wales and many Healthcare Trusts across England.

The MC3 can be used safely with ventilated patients at risk of contracting ventilated associated pneumonia (VAP). MC3 is for those people who depend on or require assistance for mouth care and for people where conventional methods such as toothbrushes and sponge swabs are not suitable.

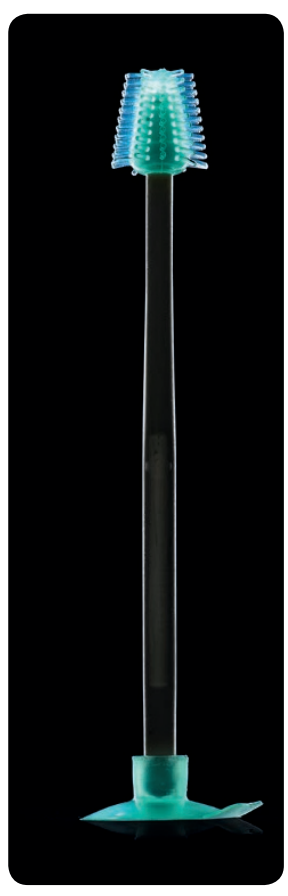

MC3 can be used to

cleanse the soft tissues inside or around the mouth for a wide range of people, including the edentulous. It can be used wet or dry to lubricate and moisten the lips and mouth with water, water based gels and mouth rinses; clean a coated tongue; remove retained food and debris from the mouth; remove sticky tenacious secretions, crusty plugs on the palate and stringy saliva; and aid oral densensitisation for patients with special requirements and learning disabilities.

The MC3 is suitable for use by any healthcare professional in hospitals, care, nursing and residential homes, hospices, community health and social service teams and in dental practices.

For more details contact Linton Whyte on 07877547762 or lintonwhyte@live.co.uk. 